\title{
Isolation and characterization of psittacine beak and feather disease virus in Saudi Arabia using molecular technique
}

\begin{abstract}
Psittacine Beak and Feather Disease (PBFD) is a contagious, fatal viral disease that affects the beak, feathers, and immune system of wild and captive old and New World Psittacine. PBFD is characterized by feather abnormalities, beak and claw deformities and eventually dying as a result of immunosuppressant. The disease is caused by member of the genus circovirus in the family Circoviridae. The disease diagnosed by clinical signs and laboratory detections. The serological diagnosis by haemagglutination (HA) and haemagglutination inhibition (HI) is subjective but molecular technique using Polymerase chain reaction (PCR) is the most reliable means for confirming the presence of the PBFDV ambience DNA genome in whole blood or tissue samples. Many birds were presented to the veterinary clinic with clinical signs of PBFD. No reports document the presence of PBFDV in KSA to date. Therefore, the objective of this work was to investigate the presence of PBFDV in KSA using PCR. Total 175 samples (blood and feathers) from clinically-suspect, and apparentlyhealth birds from 10 different psittacine species were collected, DNA was extracted and conventional PCR was performed. The viral DNA was identified in six samples $(6 / 175)$ four Grey parrots (Psittacus erithacus), and two ring necks (Psittacula eupatria eupatria). PBFDV was identified for the first time in the Kingdom of Saudi Arabia (KSA). During this investigation, we developed a technique for faster and simpler processing of multiple feather samples. The isolated PBFDV could be characterize and use as positive control for further research purpose. We recommend that the Rep gene feather-based PCR technique be established as a routine diagnostic tool in quarantine facilities across the country.
\end{abstract}

Volume 2 Issue I - 2017

\author{
A Hakami,' A Al-Ankari, ${ }^{2}$ M Zaki, ${ }^{2}$ A Yousif ${ }^{2}$ \\ 'Sabya Municipality, King Fiasal University, Saudi Arabia \\ ${ }^{2}$ Avian Diseases, King Fiasal University, Saudi Arabia
}

Correspondence: Alaudeen Hakami, Sabya Municipality, Main road, Sabya, Gizan, Saudi Arabia, Tel 00966557669995, Email hakamialaa@hotmail.com

Received: May II, 2017 | Published: June 06, 2017

Keywords: psittacine beak and feather disease, polymerase chain reaction, Saudi Arabia, grey parrot, psittacus erithacus

Abbreviations: PBFD, psittacine beak and feather disease; HI, haemagglutination inhibition; HA, haemagglutination; PCR, polymerase chain reaction; KSA, kingdom of Saudi Arabia; RT, room temperature

\section{Introduction}

Psittacine beak and feather disease (PBFD) was first described in Australian cockatoos in early 1970s. The disease was characterized by varying degrees of symmetric feather dystrophy and loss. PBFD outbreaks of wild populations are still common in Australia while outbreaks of captive birds occur worldwide. ${ }^{1}$ Antibody detection tests, commonly used in identification of PBFDV are HA and HI, but their results are subjective. ${ }^{2}$ However, to overcome this problem, PCR have been developed for identification and classification of several pathogens including PBFDV. These molecular techniques offer higher sensitivity and specificity compared to serological test. ${ }^{3}$ In addition, PCR based diagnosis can be used for identification of both clinically suspect, and apparently health carrier cases of PBFD. ${ }^{4}$ A previously described Rep gene-based PCR assay ${ }^{5}$ was used in this investigation. This technique utilizes a highly conserved region of the PBFDV ORF 1 (the rep gene) that can reliably use for sequence comparisons and phylogenetic tree analysis. The clinical manifestations of PBFD have been observed in the KSA. However, no scientific reports document the presence of PBFDV in KSA psittacine populations to date. ${ }^{6}$ Therefore, the objective of this work was to investigate the presence of PBFDV in KSA psittacine populations and to determine if it is feasible to monitor the presence of the virus routinely. The most serious problem facing this investigation was the absence of a proper positive control. The PCR experiment had to be optimized without the importation of possibly infectious material from other laboratories. This decision was made in order to eliminate possible risks associated with handling and importation of exotic avian disease agents into the country. The knowledge of the presence of PBFDV in the KSA and availability of the technology for its diagnosis is extremely important for the development of proper disease control programs for the preservation of the psittacine bird populations in the country.

\section{Materials and methods}

\section{Summary description of the experimental design}

This investigation was designed to detect the presence of PBFDV in psittacine populations in the KSA. The detection method selected was an ORF1 PCR assay that was proven highly sensitive in the detection of the virus from various clinical specimens. The bird samples targeted were feathers and blood (when available). These sample types were reported to be the best for PCR-based detection of the virus. The samples were collected from the different bird populations and species where access was permitted. It was recommended that a total of 250 birds be sampled for this investigation because of the reported high prevalence of the virus in wild and domestic psittacine populations worldwide; ultimately, only 175 samples were available for PCR analysis. DNA was extracted from the different clinical samples using commercial kits that ensured high yield and 
purity. DNA was then tested for the presence of the PBFDV ORF 1 sequences using the reference primers. Avian mitochondrial DNA from each extracted sample was targeted for PCR amplification in separate reactions to ensure that sufficient amounts of sample DNA were extracted, and introduced in the diagnostic PBFDV PCR master mix (Quality control).

\section{Sample collection and preservation}

Samples from 19 clinically-suspected (Figure 1), and 156 apparently-health birds were collected. Samples included chest feathers and whole blood. Blood was collected either by puncturing the wing vein using sterile disposable needle, or by clipping one of the nails off the claw. Blood was collected directly into $1.5 \mathrm{ml}$ sterile centrifuge tubes. Feather samples were plucked from the chest area or, collected from the bird's environment and were placed in sterile test tubes. Both sample types were labeled and stored in separate freezer boxes at $-80^{\circ} \mathrm{C}$ in the Avian Diseases Laboratory, College of Veterinary Medicine and Animal Resources, King Faisal University, Al-Ahsa, KSA. The bird species sampled during this investigation belonged to the following genera: Sulphur-crested cockatoos (Cacatua galerita), Indian ringneck (Psittacula eupatria eupatria), Local ringneck parrot (Psittacula eupatria), Lovebird (Agapornis roseicollis), Cockatiel (Nymphicus hollandicus), Senegal parrot (Poicephalus senegalus), African grey (Psittacus erithacus), Fisher (Agapornis fisheri), Macaw (Ara macaw), and Amazon (Amazona autumnalis).

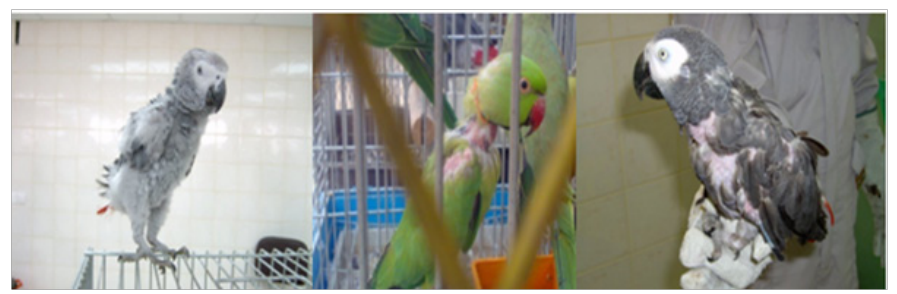

Figure I Clinically suspected birds showed symmetric feather dystrophy and loss.

Samples from different locations in Eastern and Southern provinces of KSA were collected (Figure 2).

$\mathrm{A}=$ Eastern provinces, $\mathrm{B}=$ Southern provinces. Bird samples were collected over a period of three years starting from 2008 and ending early 2010 . The reason for this was to identify a possible introduction time for the virus. Only 8 samples were collected at the end of 2008, 48 samples during the first months of 2010 and the rest of the 175 samples during 2009 .

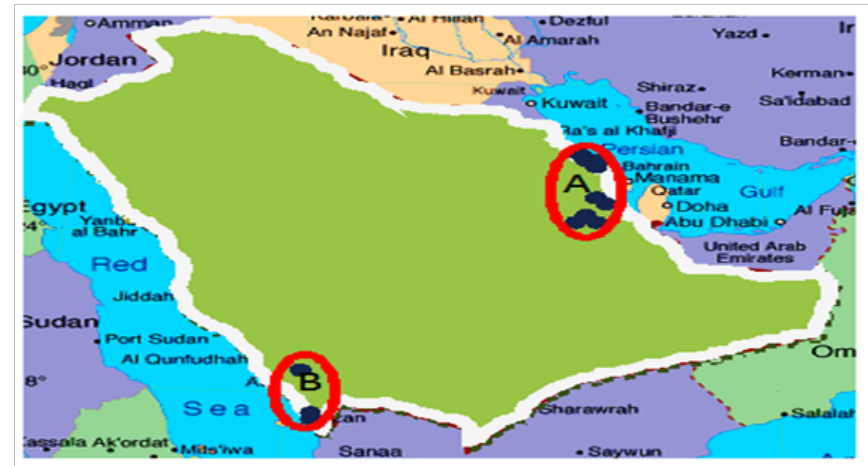

Figure 2 Samples from different locations in Eastern and Southern provinces of KSA were collected.

\section{DNA extraction from blood}

DNA was extracted from blood samples using DNeasy Blood and Tissue kit (Qiagen, Cat. 69504, USA). Extraction was performed according to the manufacturer's instructions. Briefly, blood tubes were allowed to thaw at room temperature (RT). Twenty microliters of proteinase $\mathrm{K}$ were pipetted into the bottom of the microcentrifuge tubes containing the blood sample. The volume was then adjusted to $220 \mu l$ with PBS. Two hundred microliters of buffer AL were further added and mixed by pulse-vortexing for 15 seconds, or until clotted blood was completely submerged in the lysis buffer. Samples were incubated for $10 \mathrm{~min}$ at $56^{\circ} \mathrm{C}$ to allow for digestions, and then spun down briefly to remove drops from the inside of the lid. Two hundred microliters of $100 \%$ ethanol were added, mixed for 15 seconds pulse-vortexing, and briefly centrifuged again. The mixture was then transferred to a DNeasy mini spin column inserted in a $2 \mathrm{ml}$ collection tube, and centrifuged at $8,000 \mathrm{rpm}$ for $1 \mathrm{~min}$, the flow-through and collection tube were discarded and the spin column transferred into a new collection tube. Five hundred microliters of buffer AW1 were added to the tube, and centrifuged as before. DNeasy mini spin column was then transferred to a clean collection tube, $500 \mu \mathrm{l}$ buffer AW2 were added, and centrifuged at $14,000 \mathrm{rpm}$ for $3 \mathrm{~min}$. DNeasy mini spin column was transferred to a new $1.5 \mathrm{ml}$ microcentrifuge tube, $200 \mu$ l buffer AE were added and the column was incubated at RT for 1min to allow for DNA elution. Eluted DNA was collected by centrifugation at $14,000 \mathrm{rpm}$ for $1 \mathrm{~min}$. DNA extracts were preserved at $-80^{\circ} \mathrm{C}$ until testing.

\section{DNA extraction from feather}

Viral DNA was extracted from feather samples using JETQUICK Tissue DNA Spin Kit, (Cat. No. 450 050, GENOMED GmbH, Germany). Briefly, feathers were allowed to thaw at RT before processing. Distal, differentiated portions were cut off and discarded. The growing tips were retained for DNA extraction. Tips were cut into small pieces using a sharp scalpel on a fresh piece of disposable aluminum foil for each. Cut tips were then crushed using the broad end of the scalpel blade. Crushed tips were transferred into fresh microfuge tube, and lysis buffer was added according to the manufacturer's instructions. For confirmation of direct extraction from crushed tips, duplicates of some of the samples were homogenized in a sterile mortar and pestle using sterile sand and PBS prior to addition to lysis buffer. Twenty microliters of proteinase $\mathrm{K}$ were pipetted into the bottom of the $1.5 \mathrm{ml}$ microcentrifuge tube containing the crushed, or homogenized, tips. Two hundred microliters of buffer T1 were added, and mixed thoroughly by inverting the reaction tube several times. Tubes were then incubated for $1-2 \mathrm{~h}$ at $56^{\circ} \mathrm{C}$ to allow for digestion. Tubes were then spun down briefly to remove drops from the inside of the lid. Two hundred microliters of Buffer T2 were added, mixed thoroughly by vortex, and incubated for $10 \mathrm{~min}$ at $70^{\circ} \mathrm{C}$. The mixture was allowed to cool down for approximately $1 \mathrm{~min}$. Two hundred microliters of absolute ethanol were added to each extraction tube. The mixture was then transferred to the reservoir of the micro-spin column and centrifuged at $10600 \mathrm{rpm}$ for $1 \mathrm{~min}$. The flow-through was discarded and $500 \mu \mathrm{l}$ of reconstitution buffer TX were pipette into the reservoir. The spin columns were centrifuged for $1 \mathrm{~min}$ at $10600 \mathrm{rpm}$. The flow-through was discarded and five hundred microliters of buffer T3 were added to the reservoirs. Tubes were centrifuged as before. The flow-through was discarded, columns were replaced in the collection tubes, and centrifuged for $1 \mathrm{~min}$ at $13,000 \mathrm{rpm}$ to remove residual buffer T3. The micro-spin columns were transferred to new 
$1.5 \mathrm{ml}$ microcentrifuge tubes, $200 \mu 1$ of $10 \mathrm{mM}$ Tris-HCL buffer [pH 9.0] pre-warmed to $70^{\circ} \mathrm{C}$ were added, incubated at room temperature for $5 \mathrm{~min}$ and finally centrifuged subsequently for $2 \mathrm{~min}$ at $13,000 \mathrm{rpm}$.

\section{Determination of extracted dna quality and quantity}

DNA concentration and purity was determined spectrophotometrically using SmartSpecTM Plus spectrophotometer (BioRad, Hercules, CA, USA). Purity was determined by $260 / 280 \mathrm{~nm}$ ratios using distilled water for blanking. DNA integrity was determined by electrophoresis in $1 \%$ Ethidium bromide-stained agarose gels using TAE at $5 \mathrm{~V} / \mathrm{cm}$ for $20 \mathrm{~min}$ at $\mathrm{RT}$. DNA was visualized in a UV transilluminator (Gel Doc XR gel documentation system, BIO-RAD laboratories, Milan, Italy). PCR A 603-nt fragment (Nucleotides 178-780) of the PBFDV genome was amplified using PCR with the primers 5'-TTAACAACCCTACAGACGGCGA-3' and 5'-GGCGGAGCATCTCGCAATAAG-3 ${ }^{\prime}{ }^{5}$ Primers amplify a region of the viral genome within the coding region of the Rep protein. A 530-nt fragment of the avian mitochondrial DNA $12 \mathrm{~S}$ rRNA gene was also amplified using the primers L-12SA 5'-AAACTGGGATTAGATACCCCACTAT-3' and H-12SB2 5 -TTCCGGTACACTTACCTTGTTACGAC- $3{ }^{\prime}{ }^{7}$ The mitochondrial DNA was amplified as a control for the presence of avian DNA in extracts and the absence of reaction inhibitors. Amplification reactions were carried out using the HotStar Taq ${ }^{\circledR}$ Plus Master Mix PCR kit (QIAGEN, Hilden, Germany). Each reaction tube contained 1 unit of HotStar Taq ${ }^{\circledR}$ Plus DNA polymerase in $1 \times$ PCR buffer containing $(\mathrm{KCl}$ and (NH4)2SO4), 200uM of each dNTP, $0.5 \mu \mathrm{M}$ of each of the forward and reverse primers, $1 \times$ CoralLoad dye mix, and $3 \mu$ of the sample DNA and controls. The reaction tubes were centrifuged at $2000 \times \mathrm{g}$ briefly, and placed in a BioRad MyCyclerTM thermal cycler (BioRad, Hercules, CA, USA). Thermal cycling conditions for amplification of viral and avian DNA targets genes were: an initial denaturation step $\left(95^{\circ} \mathrm{C}\right.$ for $\left.4 \mathrm{~min}\right), 38$ amplification cycles $\left(95^{\circ} \mathrm{C}\right.$ for $30 \mathrm{sec}, 54.5^{\circ} \mathrm{C}$ for $30 \mathrm{sec}$, and $72^{\circ} \mathrm{C}$ for $\left.50 \mathrm{sec}\right)$, and a final extension step $\left(72^{\circ} \mathrm{C}\right.$ for $5 \mathrm{~min})$. After amplification, $15 \mu \mathrm{l}$ of each sample were analyzed by electrophoresis on a $1.2 \%$ agarose gel stained with Ethidium bromide $(0.5 \mu \mathrm{g} / \mathrm{ml})$. DNA bands were visualized by UV irradiation in a Gel Doc XR gel documentation system (BIO-RAD laboratories, Milan, Italy).

\section{Results}

\section{Recovery of DNA from avian samples}

Blood and feather samples subjected for DNA extraction yielded concentrations from 1-11 Kocher $\mu \mathrm{g} / \mathrm{ml}(0.2-2.2 \mu \mathrm{g} / \mathrm{sample})$. The DNA extracted was highly pure (OD260/OD280 values ranging from 1.7-2.5).

\section{Amplification of mitochondrial DNA from avian DNA extracts}

Avian mitochondrial DNA amplification was used prior to PBFDV PCR assay to ensure that DNA concentration and quality were not factors in PBFDV PCR results. Successful amplification of a 530bp PCR product was achieved from tested avian DNA extracts at the lower and higher DNA concentration values (Figure 3). There were no indications of PCR inhibition in DNA extracts from either blood or feathers. Ten microliters of avian blood were extracted using the DNeasy Blood \& Tissue Kit (QIAGEN Sciences, Maryland, and USA). PCR was conducted using the $12 \mathrm{~S}$ rRNA gene primers. ${ }^{8}$ Lane $\mathrm{M}$, standard size marker, $\mathrm{L}_{1}$ negative control, $\mathrm{L}_{2 \& 3}$ test samples.

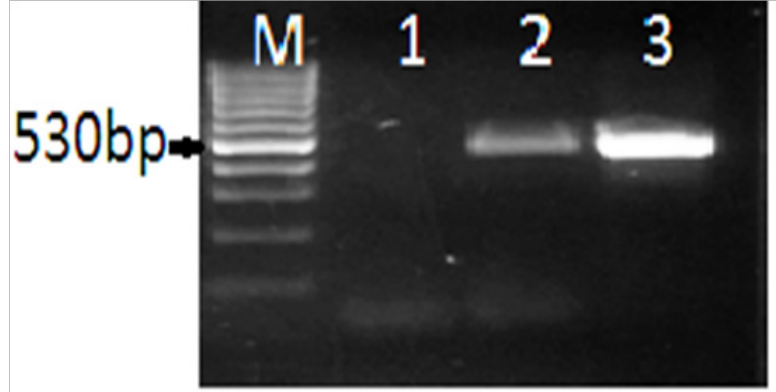

Figure 3 Amplification of mitochondrial DNA from Avian DNA extracts.

\section{NDetection of PBFDV DNA and development of PCR positive control}

DNA from $10 \mu 1$ of avian blood collected from a suspected bird was extracted using the DNeasy Blood \& Tissue Kit (QIAGEN Sciences, Maryland, and USA). PCR was conducted using the PBFDV Rep gene PCR primers as described above. A $603 \mathrm{bp}$ PCR product was amplified from the avian sample. This was the first report of PBFDV in Saudi Arabia (Figure 4, lane 2). The PCR product obtained from that first PBFDV positive sample was used as a positive control after sequence confirmation (as described below). PBFDV PCRproducts were used as templates after 1:1000 dilutions. PCR reactions produced a clear positive PCR band of the correct size (603bp). Ten microliters of avian blood collected from a suspect bird (showing clinical presentation of PBFDV) were extracted using the DNeasy Blood \& Tissue Kit (QIAGEN Sciences, Maryland, USA). PCR was conducted using the replicase-associated PBFDV gene PCR primers. Lane 1 Negative control, Lane 2 DNA extract from PBFDV positive sample, lane 3 DNA extract from PBFDV sero-negative sample, Lane 4 PBFDV PCR positive product. Lane M standard size marker.

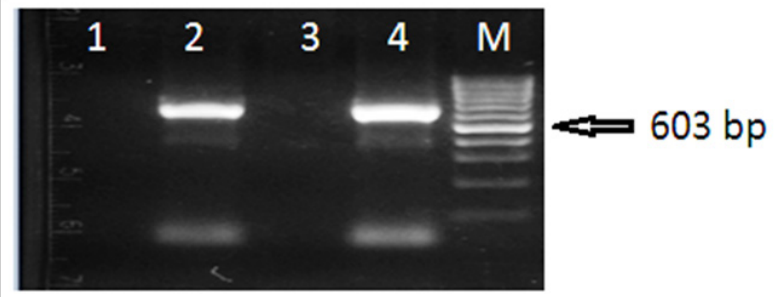

Figure 4 PBFDV Positive controls

\section{PCR screening of avian extracts for PBFDV DNA}

A total of 6 psittacine bird samples were positive using PBFDV PCR (Figure 5) (Table 1). Two positive samples were collected during 2008, 3 during 2009, and only 1 during 2010. All positive samples were collected from clinically suspected birds. Four of the positive samples were collected from Grey parrots (Psittacus erithacus) and 2 from ring neck birds (Psittacula eupatria). It was interesting to notice that the two birds from which both blood and feathers were collected, only feathers were positive to PBFDV. Only two blood samples were positive to PBFDV. All positive samples were collected from the Eastern province. PBFDV PCR screening samples Blood and feather samples were tested using the replicase-associated PBFDV gene PCR primers. Lane ${ }_{1-20 \text { (upper) }}$ screened blood samples, Lane ${ }_{1-20}$ (lower) screened feather samples. Lane ${ }_{4 \text { (upper) }}$ and lane ${ }_{1 \text { (lower) }}$ PBFDV control positive. Lane ${ }_{1 \text { (upper) }}$ and lane ${ }_{5 \text { (lower) }}$ control negative, Lane ${ }_{9 \text { (upper) }}$ and Lane $_{8 \text { (lower) }}$ standard size markers. Lanes ${ }_{1-3,5-8,}$ 10-20 (upper), Lane $_{2-7,7-20}$ (lower) test samples. 


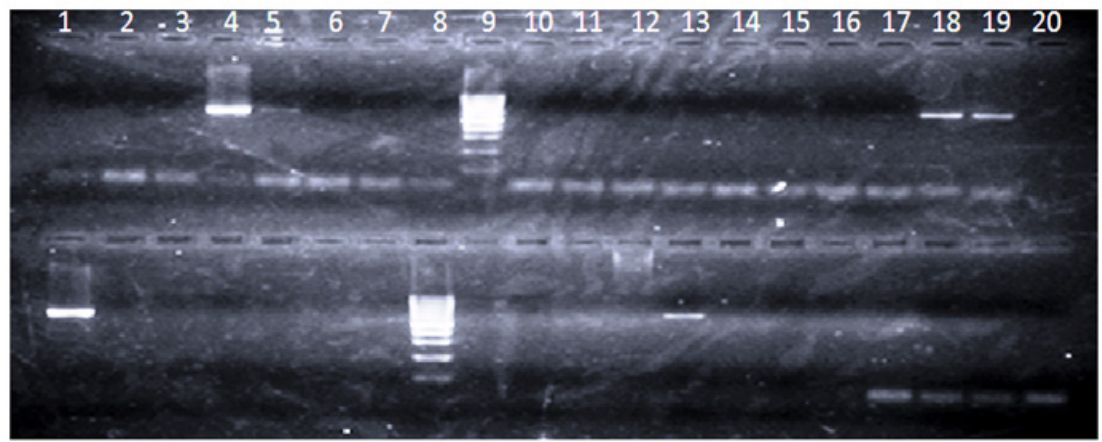

Figure 5 PBFDV PCR screening samples.

Table I Summary of PBFDV PCR screening from psittacine birds collected in the KSA

\begin{tabular}{|c|c|c|c|c|c|c|}
\hline Host species & Host common name & Sampling location & Date & Clinical status & Blood & Feather \\
\hline Psittacus erithacus & Grey parrot & Avian clinic & 2008 & $\mathrm{~S}^{*}$ & + ve & $* *$ \\
\hline Psittacus erithacus & Grey parrot & Avian clinic & 2008 & $\mathrm{~S}$ & + ve & $* *$ \\
\hline Psittacus erithacus & Grey parrot & Alqatif bird marketing & 2009 & $\mathrm{~S}$ & -ve & + ve \\
\hline Psittacus erithacus & Grey parrot & Al-ahsa bird market & 2009 & $\mathrm{~S}$ & $* *$ & $+\mathrm{ve}$ \\
\hline Psittacula eupatria & Local ringneck & Alqatif private farm & 2009 & $\mathrm{~S}$ & $* *$ & $+\mathrm{ve}$ \\
\hline Psittacula eupatria & Indian ringneck & Al-ahsa bird market & 2010 & $\mathrm{~S}$ & -ve & + ve \\
\hline
\end{tabular}

\section{Discussion}

PBFD is the most common viral disease of wild and captive psittacine birds. It has the potential to become a major threat 42 species of wild Parrots throughout the continents. ${ }^{9}$ To date, PBFDV was not reported in the KSA. Five years ago, our clinical observations claimed that PBFDV could present in the country. In order to prove or rule out this assumption, 175 psittacine blood and feather samples were collected during the years 2008-2010 and processed. ${ }^{10}$ A survey in South Africa investigated only 161 bird samples and yielded 75 positive samples. ${ }^{11}$ Therefore, considering the expected total number of psittacine birds available, 175 samples could be deemed to achieve the primary goal of detection of the virus in the Eastern and Southern provinces of Saudi Arabia. We developed a simple feathertip processing technique to reduce the need for using multiple sterile mortars. The technique relied on cutting, then crushing feather tips on sterile pieces of aluminum foil. This reduced the cost and time required for processing feather samples drastically. The technique used for processing blood and feathers was validated by assessing the DNA concentration and quality spectrophotometrically, and with the use of mitochondrial DNA PCR analysis. Our primary focus was on suspect samples showing the typical clinical presentation of PBFD. These samples were taken mainly from the avian clinic, the Veterinary Teaching Hospital, College of Veterinary Medicine and Animal Resources. It was decided that standard positive samples will not be allowed into our laboratory to avoid the possibility of contamination of the tests, and/or the environment with a novel virus. One blood sample collected in late 2008 produced the expected size PCR product in gel analysis. We intended to sequence the PBFD PCR positive products, and subsequently, use as control positive for field investigations. Positive samples identified were at the lower limit of the test detection capacity (Figure 4). Serial dilution of positive samples did not result in PCR amplification. This forced us to develop a PCR positive control for the PBFDV PCR assay using diluted PCR products. Up to 103 dilution of the positive control gave a strong PCR product in Rep gene PCR assays (Figure 5). The optimized control positive DNA will be used for research purposes. Only six samples tested positive for PBFDV (3.42\%). All positive samples were suspected cases $(31.6 \%$ of suspect birds). The majority of suspected cases $(68.42 \%)$ were PBFDV-negative. Surprisingly, PBFDV was not detected in any of the apparently normal birds. Latently infected birds can cause a severe environmental contamination. ${ }^{7,12}$ Latent infections have been reported to be the majority of infections in captive psittacine populations. ${ }^{13}$ The small number of positive samples detected in this relatively large sample size and the absence of detectable latent infections may be attributed to:

I. Intensive breeding of psittacines in Saudi Arabia is a relatively a new practice; which would reduce the chance of horizontal and vertical transmission of the virus reported by others. ${ }^{13}$

II. Psittacines imported into Saudi Arabia are from the new world; which suffers a lower prevalence of the virus. ${ }^{14}$

Another interesting finding is that positive samples were only found in 2 out of 13 bird species (Table 1) investigated. The ring-neck is bread easily in Saudi Arabia. The African grey parrot is expensive and owners are willing to spend money to try to treat infected birds. Therefore, it is possible that the virus was detected in both but not in other species where breeding is less likely, or the cost is low enough to discourage taking care of sick birds (which would lead to discarding the bird when clinical signs appear). Moreover, two of the positive samples were only positive upon testing feathers and not blood. This pointed to the importance of feather sample testing for screening of birds for PBFDV.

\section{Conclusion}

It is important not to consider the $4 \%$ to be a real indication of the prevalence of the disease in KSA. It should be taken only as an indicator for the need to further investigate the prevalence of the disease in the different avian farms and at ports. In support of this conclusion is the 
fact that the six positive samples were from suspected cases. PCR is the only tool to be recommended to detect cases with PBFD, as some other diseases and manifestation show similar clinical signs. ${ }^{15}$ This technique is an excellent tool to be used for easy an epidemiology studies for the PBFD in Saudi Arabia. This study recommends all imported birds are subject to be tested for PBFD by using PCR in order to prevent entry of the virus.

\section{Acknowledgements}

This project was funded by the Deanship of Scientific Research, King Faisal University. The technical assistance of Dr. Mohammad Al-kahtani. King Faisal Special Hospital and Research Centers, Riyadh, was appreciated.

\section{Conflict of interest}

We declare that there is no financial interest or any conflict of interest exists.

\section{References}

1. Pass DA, Perry RA. Psittacine Beak and Feather Disease:An update Aust Vet J. 1984;61(3):69-74.

2. Johne R, Raue R, Grund C, et al. Recombinant expression of a truncated capsid protein of beak and feather disease virus and its application in serological test. Avian Pathol. 2004;33(3):328-336.

3. Bonne N, Shearer P, Sharp M, et al. Assessment of recombinant beak and feather disease virus (BFDV) capsid protein as a vaccine for psittacine beak and feather disease (PBFD). J Gen Virol. 2009;90(3):640-647.

4. Hess M, Scope A, Heincz U. Comparative sensitivity of polymerase chain reaction diagnosis of psittacine beak and feather disease on feather samples, cloacal swabs and blood from budgerigars (Melopsittacus undulates, Shaw 18005). Avian Pathol. 2004;33(5):477-481.
5. Ritchie PA, Anderson IL, Lambert DM. Evidence for specificity of psittacine beak and feather disease viruses among avian hosts. Virol. 2003;306(1):109-115.

6. Hakami A, Al-Ankary A, Zaki M, et al. Beak and Feather Disease Virus in the Kingdom of Saudi Arabia. 2010.

7. Ritchie B. Function and Control. In: Avian Viruses. USA: Wingers Publishing; 1995. p. 223-252.

8. Ritchie B, Niagro F, Latimer K, et al. A review of psittacine peak and feather disease. J Assoc Avian Vet. 1989;3:143-149.

9. Saif Y, Barnes H, Glisson G, et al. Disease of poultry. 11th ed. USA: Iowa State Press; 2003.

10. Shearer PL, Bonne N, Clark P, et al. Beak and feather disease virus infection in cockatiels (Nymphicus hollandicus). Avian Pathol. 2008;37:75-81.

11. Kondiah K, Albertyn J, Bragg R. Genetic diversity of the Rep gene of beak and feather disease virus in South Africa. Arch Virol. 2006;151:2539 2545 .

12. Dahlhausen S, Radabaugh M. Update on psittacine beak and feather disease and avian polyomavirus - epidemiology and diagnostics. Aust Vet Proced. 1997:51-57.

13. Rahaus, M, Desloges N, Probst S, et al. Detection of beak and feather disease virus DNA in embryonated eggs of psittacine birds. Veterinarni Medicina. 2008;53(1):53-58.

14. Bert E, Tomassone L, Peccati C, et al. Detection of beak and feather disease virus (BFDV) and avian polyomavirus (APV) DNA in psittacine birds in Italy. Vet Med B Infect Dis Vet Public Health. 2005;52:64-68.

15. Schat K. Circovirus infections. Diseases of Poultry. In: Saif Y, Fadly A, Glisson J, McDougald L, Nolan K, Swayne D, editors. 11th ed. USA: Iowa State Press; 2003. p. 181-201. 